\title{
Periprostetik eklem enfeksiyonlarında tek aşamalı revizyon
}

\author{
Single stage revision in the treatment of periprosthetic joint infections
}

\author{
Ömer Selim Yıldırım, Murat İpteç
}

Atatürk Üniversitesi Tıp Fakültesi, Ortopedi ve Travmatoloji Anabilim Dalı, Erzurum

Periprostetik eklem enfeksiyonlarının tedavisinde, revizyon artroplastisi, tedavi sürecinde ana unsuru oluşturmaktadır. Revizyon artroplastisi, tek ve iki aşamada değişim olarak ikiye ayrılır. Tek aşamalı değişimin iki aşamalıya göre bazı avantajları vardır: tek operasyonun olması, sistemik antibiyotik kullanımının azalması, hastanede yatış süresinin az olması, görece artmış hasta memnuniyeti ve fonksiyonel artış, morbiditenin ve masrafların azalması. Bu yüzden uygun seçilen vakalarda, tek aşamalı artroplasti revizyonu ile başarılı sonuçlar elde etmek mümkündür.

Anahtar sözcükler: protez eklem enfeksiyonu; tek aşamalı revizyon; kalça ve diz değişim artroplastisi
Revision arthroplasty in the treatment of periprosthetic joint infection comprises the main element of the treatment process. Revision arthroplasty has two options, single and double stage exchange. Single stage revision offers some advantages over double stage revision. These are: need for one operation, reduced use of systemic antibiotics, short term hospitalization, relatively increased patient satisfaction, improved functional outcomes, decreased morbidity and reduced cost. So it is possible to achieve successful outcomes with single stage revision arthroplasty in appropriately selected patients.

Key words: periprosthetic joint infection; single stage revision; hip and knee exchange arthroplasty
B ütün artroplastiler için enfeksiyon oranı ortalama \%1,25 olarak bildirilmiştir. ${ }^{[1]}$ Kalça ve diz artroplastisi sonrası periprostetik enfeksiyon oranı, nadir olarak, primer kalça artroplasti hastalarının \%0,3-2,9'unda, primer diz artroplastilerinin ise \%0,5-2'sinde meydana gelmektedir. ${ }^{[2-4]}$ Yaşam beklentisinin ve yaşlı nüfusun fonksiyonel beklentilerinin artmasının sonucu olarak; Birleşik Devletler'de, 2030 yılında yıllık olarak, primer kalça ve diz artroplasti uygulamalarının sayısının, sırasıyla, $\% 174$ ve $\% 673$ artacağı tahmin edilmektedir. Bu nedenle, periprostetik eklem enfeksiyonları, gelecekte öngörülebilir bir ekonomik yük ve önemli bir komplikasyon olmaya devam edecektir. ${ }^{[5]}$

Periprostetik eklem enfeksiyonları; total kalça artroplastisi revizyonu için üçüncü en sık $(\% 14,8)$, total diz artroplastisi için ise en sık $(\% 25,2)$ revizyon nedeni olarak karşımıza çıkmaktadır. ${ }^{[6,7]}$

Revizyon prosedürünün esas hedefi, enfeksiyonu ortadan kaldırmak ve ağrısız, işlevsel ve stabil bir diz ya da kalça eklemi oluşturmaktır. ${ }^{[8]}$ Periprostetik eklem enfeksiyon tedavisinin modern biçimi ancak hasta merkezli yaklaşımla sağlanabilir. ${ }^{[9]}$

Artroplastilerde enfeksiyon, ortopedik cerrahı zorlayan komplikasyonların başında gelir. Değişim artroplastisi, periprostetik enfeksiyon tedavisinde etkin bir yöntem olarak kullanılmaktadır. Kronik enfeksiyonun cerrahi yönetiminde, Kuzey Amerika ve Birleşik Krallık'ta, iki aşamalı değişim altın standart prosedür olarak uygulanmaktadır. Bu prosedür, ilk aşamada; enfekte implantın çıkarılması, radikal debridmanı, geçici antibiyotikli çimentonun ilk aşamada yerleştirilmesini içerir. Sonraki rekonstrüksiyon aşamasında; kalıcı protez ile çimentonun yerleştirilmesini, belirlenmiş bir periyod boyunca, altı hafta veya daha fazla sistemik antibiyotik tedavisini gerektirir. ${ }^{[10,11]}$

Tek aşamalı değişim artroplastisi, ilk olarak 1981'de Bucholz tarafindan, sonra da 1985 'te Freeman tarafından tanımlanmış ve birçok Avrupa merkezinde umut verici sonuçlarla birlikte popülerlik kazanmıştır. ${ }^{[12-14]}$

- İletişim adresi: Dr. Ömer Selim Yıldırım, Atatürk Üniversitesi Tıp Fakültesi, Ortopedi ve Travmatoloji Anabilim Dalı, Erzurum Tel: 0532 - 4411987 e-posta: osyildirim@yahoo.com

- Geliș tarihi: 1 Mart $2016 \quad$ Kabul tarihi: 1 Mart 2016 
Zimmerli ve arkadaşları; enfeksiyonun süresi, yumuşak dokunu durumu, antibiyotik tedavisine ve cerrahi sürece kılavuzluk edecek, mikroorganizmanın tipi ve duyarlılığı gibi faktörlerin olduğu bir protokol tanımlamışlardır. ${ }^{[15]}$

Mevcut literatüre göre; hastaların belli şartlar ile seçiminden dolayı, tek aşamalı değişimin iki aşamalı değişim ile doğrudan karşılaştırılması zordur. ${ }^{[16]}$

Beswick ve arkadaşları, bir ve iki aşamalı yöntemlerin arasında, yeniden enfeksiyon oranları bakımından, literatürde herhangi bir farklılık olmadığını bildirmişlerdir. ${ }^{[17]}$

Enfeksiyon tedavisinde tek aşamalı ve iki aşamalı değişim yaklaşımlarında, benzer başarı oranları görülmekle birlikte, tek aşamalı değişim görüşünün önemli potansiyel avantajı, yalnızca bir cerrahi prosedürün uygulanır olmasıdır. Bu prosedür; operasyonlara bağıı riski azaltır, fonksiyon kaybını azaltır; azalmış toplam maliyet ve finansal avantaj, daha kısa süreli hastanede kalış ve daha kısa süreli sistemik antibiyotik uygulamasını ve görece artmış hasta memnuniyetini sağlar. ${ }^{[18,19]}$

Bütün ekipmanın dikkatli bir şekilde çıkarılması, çimento ve etkilenen yumuşak dokuların zorunlu agresif debridmanı, bu teknikte gereklidir. ${ }^{[20]}$ Tek aşamalı değişim için \%73-100 arasında başarı oranları bildirilmiştir. ${ }^{[21-23]}$ Yine, ABD ve Kuzey Avrupa'da yapılan çaIışmalarda da başarılı sonuçlar bildirilmiştir. ${ }^{[24,25]}$ Tek aşamalı değişim cerrahisi uygulamasında, klinik çalışmaların eksikliği ve deneyim gerektirmesi göz önüne alınmalıdır.

Tek ya da çift aşamalı cerrahilerin her ikisinin de kendine has avantaj ve dezavantajları vardır. Sıklıkla enfeksiyon eradikasyonu ve rekonstrüktif prosedürlere odaklanmamıza rağmen, hastanın sosyal özellikler ve biyolojik özellikleri karar vermemizi etkileyecektir. Cerrah, bütün şartları değerlendirerek, seçenekleri değiştirebilir.

Ayrıca, Birleşik Devletler kaynaklı başka bir çalışmada ise, kalçanın iki aşamalı yaklaşımının yüksek mortalite (\%7) ile ilişkisi bildirilmiştir. ${ }^{[26]}$ Bir çalışmada ise, iki aşamalı değişimin enfeksiyon kontrolünde daha şanslı, ancak daha yüksek mortalite oranına sahip olduğu bildirilmiştir. Bu teorik modelde, tek aşama, çift aşamaya tercih edilmiştir. Anlayışımızı geliştirmek için, daha kapsamlı çalışmalara ihtiyaç vardır. ${ }^{[27]}$

\section{ETIYOLOJi VE SINIFLAMA}

Literatürde, tek aşamalı değişim artroplastisi için uygun aday seçimi hâlâ tartışmalıdır. ${ }^{[28]}$ Birleşik Krallık'ta yayımlanan bir makalede, tek aşamalı seçeneği dahil kılan veya hariç bırakan kriterler bildirilmiştir.
Eklemden kaynaklanan sepsise ikincil olarak gelişen akut dekompanse ve immün sistemi baskılanmış hastalarda, tek aşamalı değişim girişiminin yapılmaması hususunda genel bir görüş birliği vardır. ${ }^{[15,29]}$ Patojenin bilinmemesi, yüksek derecede virülansa ya da çoklu ilaç direncine sahip mikroorganizma varlı̆̆ı, önemli ölçüde yumuşak dokuyu sarmış olması tek aşamadan vazgeçiren sebeplerdir. Karaciğger yetmezliği ve böbrek yetmezliği gibi önemli medikal komorbid durumların varlığı, rölatif kontrendikasyon oluşturmaktadır. Bu gibi vakalarda, iki veya daha çok aşamalı değişim düşünülmeli ve çoklu bir disiplin çerçevesinde değerlendirme yapılmalıdır. ${ }^{[30]}$

Periprostetik kalça enfeksiyonlarının olduğu bir prospektif kohort çalışmasında, tedavi karar ağacı olarak ifade edilen bir şema belirlenmiştir. Bu şemada, tek aşamalı değişim tercihi şu şekilde sıralanmıştır:

- Çok yüksek operasyon riski ya da cerrahi hasta reddi yoksa,

- semptomlar iki haftadan az, implantasyon bir aydan kısa sürede yapılmış ve protez stabil değil ise,

- siddetli kemik kaybı ve çok yüksek yeniden enfeksiyon riski yok ise,

- Kemik grefti ihtiyacı yok ise ya da operasyon öncesi mikroorganizma izole edilemediyse,

tek aşamalı değişim artroplastisi uygulanabilir. ${ }^{[31]}$

Yapılan bir çalışmada sunulan, klinik bulgulara dayanan enfeksiyon sınıflandırma sistemine göre, Evre 3 ya da Evre 4 durumlarında tek aşamalı değişim tercih edilebilir (Tablo 1). ${ }^{[32]}$

Kronik akan sinüs varlığı kötü prognoz kriteridir. Bu hastalarda iki aşamalı değişim düşünülmesi gerektiği ve tercih edilen bir çalışmada da eradikasyon oranı \%92 olarak bildirilmiştir. ${ }^{[3]}$ Ancak, tek aşamaI çimentolu kalça değişim artroplastisinin ortalama yedi yıllık sonuçlarında, \%85'in üzerinde başarı oranı da bildirilmiştir. ${ }^{[34]}$ Operasyon öncesi tanımlanmış bir duyarlı patojenin, operasyon öncesi radyografilerde minimal-orta kemik kaybının ya da fistül ya da sinüs varlığından bağımsız olarak yeterli yumuşak dokunu varlığı durumunda ve debridman sonrası yumuşak doku kaybı beklenmeyen hastalar için tek aşama tercih edilebilir. Hastaları immünolojik ve hemodinamik olarak tehlikeden uzak tutacağı ve hastaların anesteziyi tolere edebileceği uzunlukta revizyon prosedürleri uygulanmalıdır. ${ }^{[35,36]}$

Bu hastalar için; ortopedistin, enfeksiyon hastalıkları uzmanının ve mikrobiyoloğun olduğu, çoklu disiplinli bir bireysel değerlendirme gereklidir (Tablo 2). 
Haddad ve arkadaşlarının yayımladığı bir makalede, tek aşamalı revizyon cerrahisindeki endikasyonları; sağıklı yumuşak doku, çimentolu femoral rekonstrüksiyona izin verecek minimal kemik kaybı, organizmanın ve duyarlılığının bilinmesi olarak ifade edilmiş̧tir. Görece kontrendikasyonlar, risk faktörleri ise Tablo 3'te sıralanmıştır.
Artroplasti cerrahlarının ve araştırmacılarının yaptığı, 2014 yılındaki uluslararası bir toplantıda, çift aşamalı değişimin tek aşamalı değişime tercih edilmesini gerektiren bir takım durumlar, $\% 78$ oranında güçlü bir fikir birliği ile belirtilmiştir. Bunlar; yaygın sepsis varlığı, tanımlanamayan bakteri enfeksiyonu, ilaca dirençli bakterinin neden olduğu enfeksiyon, sinüs traktının

Tablo 1. Klinik bulgulara dayanan enfeksiyon sınıflandırma sistemi

\begin{tabular}{lll}
\hline & Durum & Tedavi \\
\hline 1. Derece & Operasyonda pozitif kültür (ikiden fazla) & Uygun antibiyotik tedavisi \\
2. Derece & Akut operasyon sonrası enfeksiyon (ilk ay) & Debridman ve protezi koruma \\
3. Derece & $\begin{array}{l}\text { Akut hematojen enfeksiyon (akut başlangıçlı semptomlar ve } \\
\text { iyi fonksiyonlu eklem) }\end{array}$ & Debridman ve protezi koruma ya da çıkarma \\
4. Derece & Geç kronik (bir aydan sonra) & Protezi çıkarma
\end{tabular}

Tablo 2. Tek aşamalı total kalça değişim artroplastisi ya da total diz değişim artroplastisi için, hastaların uygunluğunu belirleyen, dahil eden ve hariç bırakan kriterler ${ }^{[30]}$

\begin{tabular}{lll} 
& Hariç bırakan & Görece \\
\cline { 2 - 3 } Dahil eden & Kesin & Sinüs traktı veya fistül varlığı \\
\hline Immün sistemi baskılanmamış hasta & Yüksek virülans organizma & Periferik vasküler hastalık \\
Çimentıklı yumuşak dokunun varlığı & Tanımlanamayan organizma & \\
minimal/orta derecede kemik kaybı olan hasta & Çoklu ilaç direnci olan organizma & \\
Organizmanın bilinmesi & Ön görülen yumuşak doku gereksinimi \\
Organizmanın duyarlılığının bilinmesi & Önemli kemik kaybı \\
Organizmaya uygun antibiyotik varlığı & İmmünsupresyonu içeren \\
& önemli komorbid durumlar
\end{tabular}

Tablo 3. Görece kontrendikasyonlar ve risk faktörleri ${ }^{[29]}$

\begin{tabular}{|c|c|}
\hline Kategori & Risk faktörü \\
\hline \multirow[t]{3}{*}{ Lokal } & Önemli yumuşak doku riski \\
\hline & Çimentolu rekonstrüksiyonu engelleyen önemli kemik kaybı \\
\hline & Periferik vasküler hastalık \\
\hline \multirow[t]{4}{*}{ Hasta } & İmmünsupresyon \\
\hline & Eş zamanlı sepsis \\
\hline & Sistemik hastalık \\
\hline & Yeniden enfeksiyon \\
\hline \multirow[t]{5}{*}{ Organizma } & MRSA, MRSE \\
\hline & Polimikrobiyal enfeksiyon \\
\hline & Olağan dışı kommensal \\
\hline & Olağan dışı direnç profili \\
\hline & Tanımlanamayan enfekte mikroorganizma \\
\hline
\end{tabular}


varlığı ve ekleme uzanan şiddetli yumuşak doku yetersizliğidir.[16]

Tek aşamalı değişimin; morbiditeyi azalttı̆̆ı, hastanın fonksiyonunu arttırdığı ve maliyeti azalttığı belirtilmiştir. ${ }^{[37,38]}$

Bazı komorbid durumlar (obezite, diyabet, immünsupresyon, renal hastalıklar, sigara kullanımı, şiddetli kalp hastalığı, metastatik karsinom) enfeksiyon için predispozan olduğundan, tek aşama revizyon sonuçlarının başarısını tehlikeye atabilir. ${ }^{[39]}$

Periprostetik eklem enfeksiyon tedavisinde \%85'ten fazla oranda tek aşamalı değişimin kullanıldığı, ENDO Klinik merkezli bir derlemede ise; endikasyonlar arasında tecrübeli bir cerrahi ekibin gerekliliği ve cerrahinin özellikle bunun için eğitim almış cerrahlar tarafından gerçekleştirilmesi gerektiği ifade edilmiştir. Kontrendikasyonlar arasında ise, bunlarla sınırlı olmamakla birlikte; operasyon öncesi tanımlanamamış bakterinin varlığı, ikiden fazla tek aşamanın başarısız oluşu, enfeksiyonun nörovasküler demeti içermesi ve uygun antibiyotiğin olmayışı sayılmıştır. ${ }^{[10]}$

Yumuşak doku rekonstrüksiyon öngörüldüğünde de, çoklu disipliner bir yaklaşım gerekir; plastik cerrahın dahil olduğu, iki aşamalı değişim olsun ya da olmasın, ileri yara bakımının gerekli olduğu bir süreç yararlı olabilir. ${ }^{[14,40]}$

Tek aşamalı revizon için, iki aşamalı prosedüre benzer 'ikisi bir arada' tekniğinden bahsedilmiştir. Birinci ve ikinci aşama arasında, altı hafta yerine birkaç dakika vardır. Yeni steril aletlerin kullanılabileceği ikinci bir set için, yeniden cerrahi sahanın örtülmesine ve drape yapıştırılmasına yetecek kadar zaman gereklidir. İkisi bir arada prosedüründe kilit noktalar şunlardır[ ${ }^{[22,41]}$ :

- Operasyon öncesi tanımlanmış mikroorganizmanın varlığı (genellikle artroskopik), duyarlılık ve kültür için çoklu numune alınması gereklidir.

- İmplantları çıkarma ve eksiksiz olarak debridman ve irrigasyon yapılmalıdır.

- Birkaç dakika ara verilmelidir.

- Yeni örtünün, drape ve içinde protezin de bulunduğu yeni cerrahi enstrümanların kullanılması gerekir.

- Mikrobiyolojiye danışılan antibiyotiğin erken dönemde başlanılması ve altı hafta parenteral veya oral yolla devam edilmesi uygundur.

- Son mikrobiyoloji sonucuna göre antibiyotiğin ayarlanması gereklidir.

- Erken dönemde yük verilmesi ve hareket açıklığı egzersizlerine başlanılması gerekir.
Periprostetik eklem enfeksiyonları; yabancı cisim varlığından dolayı, normalden daha az sayıda etkenle ortaya çıkabilir. Bunu nedeni olarak, yabancı cisim varlığında nötrofillerin fagositoz yeterliliğinin azalması gösterilmiştir. ${ }^{[42,43]}$

\section{TANI}

Hasta, direkt olarak enfeksiyona yönelik semptomlar ve bulgular; ciltte kızarıklık ve şişlik, yara yerinde akıntı, yara yerinde açılma, lokalize ısı artışı ve sistemik ateş bulguları ile başvurulabilir. Özellikle açıklanamayan ağrısı olan hastalarda, bunlar olmadan da eklemde enfeksiyon varlığından şüphelenilmelidir. ${ }^{[44,45]}$

Tanıda, mikrobiyolojik ve serolojik numuneler gereklidir. Özellikle C-reaktif protein (CRP) ve eritrosit sedimentasyon hızı (ESR), tanıya ve tedavi cevabının değerlendirilmesine yardımcıdır. Eklem aspirasyonu, patojen etkenin tanımlanmasında ve duyarlı uygun antibiyotiğin seçilmesinde gerekli olan, yardımcı bir yöntemdir.

\section{AMELIYAT ÖNCESI PLANLAMA ${ }^{[9]}$}

Herhangi bir şüpheli periprostetik eklem enfeksiyonunda, eklem aspirasyonu zorunludur. Bu, bakterinin operasyon öncesi tanımlanmasına ve hem lokal (kemik çimentosuna) hem de sistemik antibiyotik tedavisinin planlanmasına izin verir. ${ }^{[46]}$

Aspirat araştırmaları şunlardan oluşur:

- Aspirasyondan en az 14 gün önce antibiyotiğin bırakılmasını gerektirir. En az 14 günlük bakteriyel kültür sonucu gerekir. ${ }^{[4]}$

- Aspiratta beyaz küre sayısına ve granülosit yüzdesine bakılır. ${ }^{[48,49]}$

- Bazı vakalarda; alfa-defensin test, PCR bakılabilir.

- Lökosit esteraz değerlendirilebilir.

- Klinik şüphenin devam ettiği vakalarda negatif kültür sonucu biyopsi gerektirir. ${ }^{[50]}$

Kordelle ve arkadaşları tarafından; başlangıçta total kalça veya total diz artroplastisi için aseptik revizyon planlanan hastaların \%4-7'sinde, belirgin klinik semptomlara ve laboratuvar değerlerinde yükselmelere neden olmadan, düşük dereceli enfeksiyonun varlığı gösterilmiştir. ${ }^{[9]}$

- Direkt grafi, enfeksiyon varlığının kemikten olduğunun belirlenmesinde (periostit), osteolitik kemik ya da osteomiyelit ve cansız kemik debridmanının gerekliliği için değerlendirilmelidir.

- Nadiren de olsa, nükleer görüntüleme kullanılabilir. 
- Operasyona ait genel riskler değerlendirilmelidir.

- Transfüzyon için yeterli miktarda kan bulundurulmalı ve operasyon sırasında ise traneksamik asit kan kaybını azaltmak amacı ile uygulanabilir.

Tekrarlayabilir ya da yeni enfeksiyon riskinin \%1015 olduğu, hematom, yara debridmanı ve inatçı enfeksiyon için tekrar operasyon gerekebileceği, operasyon sonrası siyatik sinir hasarı olabileceği, operasyon sırasında ve sonrasında artmış kırık riskinin olduğu, yumuşak dokunun etkilenmesinden kaynaklanan yüksek çıkık oranının varlığı hakkında hasta bilgilendirilmelidir.

Cerrah, sağlam ve iyi sabitlenen implantların farkında olmalıdır. Cerrahi, uygun implant seçimi, yetersiz kemik stoğu, fraktür ve korteks perforasyonu gibi operasyon sırasındaki komplikasyonlar göz önünde bulundurularak yapılmalıdır. Kemik kaybı, genellikle radyolojik olarak görünenden daha yaygındır. Ciddi vakalarda değişimin, öngörülen seviyenin daha distali ve daha proksimalini, hatta femur için diz eklemini de içerebileceği unutulmamalıdır.

Yüksek doz antibiyotikli çimento kullanımı, her vakada zorunludur. Hemen her zaman, en az 3-5 paket çimento gereklidir. Karıştırma sistemleri ve çimento tabancaları, ulaşılması zor bölgelerin daha etkin çimentolanmasında yardımcı olabilir. Çimentolu implantasyon öncesi, uygun ve duyarlı antibiyotik bilgisi, gereklidir.

Hastaya, yapılacak cerrahi girişim için pozisyon verilir. Kliniğimizde, kalça değişim artroplastisi için lateral dekübit pozisyon, diz değişim artroplastisi için supin pozisyon tercih edilir. Diz için, özellikle çimento ile kemik uyumunu arttırmak amacıyla, uyluk proksimaline turnike uygulaması tercih edilebilir.

Önceden hazırlanmış iodin povakrileks ve izopropil alkol karışımı ile, cilt hazırlığı yapılabilir.

\section{AMELIYAT SÜRECi}

Eski insizyon hattı kullanılmalı ve insizyon hattı üzerindeki eski skarlar eksize edilmelidir.

Sinüs traktı, cilt insizyonu ile birleştirilmeli ve eklem kapsülüne kadar radikal olarak çıkarılmalıdır. Muskülokütan flep gerekebileceğinden, plastik cerrah hazır olmalıdır. Sinüs traktı, tek aşama için kontrendikasyon teşkil etmez. Bütün ölü doku ve nekrotik kemik radikal olarak çıkarılır.

Operasyon sırasında en az beş farklı alandan kültür numuneleri, mikrobiyolojik ve histolojik değerlendirilme için alınmalıdır. ${ }^{[42,51]}$
Pulsatil lavaj, hidrojen peroksit ya da povidon iyotun, tek başına kullanıldıklarında, biyofilmin kaldırılmasında ve bu nedenle enfeksiyonun tekrarını önlemede yetersiz olduğu gösterilmiştir. Ancak, kombine kullanımları bakteri sayısının azaltılmasında yararlı olabilir. Hidrojen peroksit kimyasal debridman sağlayarak, povidon iyot ise bakterisit etkinlik ile yararlı olabilir. ${ }^{[52-54]}$ Lavaj için \%0,9'luk salin, pulsatil olarak kullanılabilir. Pulsatil lavajın vaka boyunca kullanılması önerilir. Sonra, \%3'lük hidrojen peroksit ve steril suyun eşit miktarda karışım solüsyonu ile lavaj yapılabilir. Hidrojen peroksit, ortamdan salin kullanılarak kaldırılır. Sonrasında, \%10'luk su ve dilüe povidin iyot ile irrigasyon yapılır ve yine salin kullanılarak uzaklaştırılır.

Tüm implantlar çıkarılıp ve agresif debridman tamamlandıktan sonra, intramedüller kanal polimerik biguanid-hidroklorid (poliheksanid) emdirilmiş bezlerle doldurulabilir. Ayrıca bu bezler, hastaya yeniden drape yapıştırılmadan, yara bölgesine de yerleştirilebilir.

Çimentolu implantların çıkarılması, içeri gömülmüş çimentosuz implantlardan daha kolay ve daha az invaziv olabilir. İyi tespit edilmiş çimentosuz implant kullanılan vakalarda; kortikal pencere gerekli olabilir ve burr ve testere bunun açılmasına yardım edebilir. Ancak bu, deneyimli ellerde dahi önemli bir yıkıma ve kemik stoğu kayıbına yol açılabilir. Bazen, çimentolu ya da gömülmüş çimentosuz stemin çıkarılmasında trokanterik osteotomi gerekli olabilir.

Düzgün osteotom ve keskiler ile çimento başarılı bir şekilde çıkarılabilir ve kemik kaybı önlenebilir. Bu amaçla, çeşitli ebatta osteotomlar hazır bulundurulmalıdır.

İmplantın çıkarılması için, özel ya da çok amaçlı çıkarıcılar gerekmektedir. Çok amaçlı uzun çıkarıcıların, gömülmüş implantların çıkarılmasında başarılı olduğu gösterilmiştir.

Özel kavisli keski, rongeur, küret ve drill, çimento çıkarmak için kullanılabilir.

Kemik ve yumuşak doku debridmanı, mümkün olduğu kadar radikal olmalı, osteolizin ve canlı olmayan kemiğin olduğu alanları içermelidir. Agresif debridman sonlandırıldığında, çıkarılan materyal sıklıkla, iki aşamalı debridmandan çıkarılan materyalden daha fazla olur.

Reimplantasyon için yeni enstrümanlar kullanılırken, cerrahi ekip yeniden giyinir; hastanın cerrahi sahası yeniden hazırlanır ve drapelenir.

İkinci doz antibiyotik; operasyon 1,5 saati geçtiyse ya da kan kaybı 1000 cc'den fazla olduysa yapılır. 


\section{YENI IMPLANTIN YERLEŞTIRILMESI}

Yetersiz kemik stoğu olan durumlarda allogreft kullanılabilir, ancak ideal olanı, enfeksiyon olan durumdan kaçınmaktır. Küçük-orta boyuttaki defektlerde, anitibiyotikli çimento kullanılması önerilir.

Alternatif olarak, tantalum ya da yüksek poroziteli asetabular güçlendiriciler kullanılabilir. Bu güçlendiricilerdeki uzunluk ve genişlik varyasyonları, kemik kaybı ile sonuçlanan rekonstrüksiyonun yeniden yapılandırılmasına izin verir. Sonuç olarak;kombine bir şekilde, çimento ve tantalum güçlendiriciler kullanılabilir.

Uygun antibiyotikli çimento; suda çözünebilir, bakterisidal, toz form, antibiyotik oranı polimetil metakrilat (pmma) tozu başına $10 \%$ 'u geçmeyecek şekilde olmalıdır.

PMMA'ya dahil edilecek ideal antibiyotik; geniş spektrumlu (gram pozitif, gram negatif), bakterisidik etkili, düşük oranda direnç gelişimi olmalı, toz formda bulunmalı, uygun çözünme vasfı olmalı, çimentonun polimerizasyonunu bozmama gibi özelliklere sahip olmalıdır.

Kombine antibiyotik kullanımı ise, additif etki sağlayarak, çimento ile kullanımında avantaj sağlayabilir. ${ }^{[55]}$

Revizyon için kullanılacak stem, ekstremite uzunluğunu ve anteversiyonunu ayarlayarak stabilite sağlamalı ve çıkığın önlenmesine yardımcı olacak şekilde seçilmelidir.

Tek aşamalı değişim sonrası çekilen grafiler, başlanan tedavide en üst düzeyde olumlu sonuç almak için, sürecin ilk belirteci olur (Şekil 1-3).

\section{AMELIYAT SONRASI SÜREÇ}

Sistemik antibiyotik uygulaması en az 5-14 gün boyunca yapılmalıdır. Uzamış intravenöz antibiyotik kullanımı daha çok iki aşamalıda uygulanır. Kültür sonucuna göre oral tedaviye geçilir, bu süre altı haftayı bulmalıdır. ${ }^{[29,36,56]}$ Sedim, CRP ve nutrisyonel belirteç (serum albümin, karaciğer fonksiyon testleri) takipleri, antibiyotik uygulama süresince devam etmelidir. ${ }^{[42,57]}$

Operasyon sonrası en az 14 gün yatış gereklidir. Rehabilitasyon, yumuşak doku ve kemik hasarına, enfeksiyonun genişliğine bağlıdır. Mobilizasyon 48-72 saat içerisinde sağlanmalıdır. Tam yük vererek yürüme, yeterli kemik stoğu olan hastalarda erken dönemde mümkünse sağlanmalıdır.

\section{KLINIK SONUÇLAR VE KOMPLIKASYONLAR}

Dahil eden ve hariç bırakan nedenler dikkate alınarak yapılan bazı çalışmalarda \%100 başarı oranı ifade edilmiş olsa $\mathrm{da}^{[58,59]}$, inatçı ya da yeniden enfeksiyonun varlığı, tek aşamadaki süreç ile en ilişkili komplikasyon olarak karşımıza çıkmaktadır. Tek aşamalı değişimde, dirençli olmayan enfeksiyonda, yeniden enfeksiyona bağlı başarısızlık oranları \%9-18 arasında bildirilmiştir. ${ }^{[60-63]}$

Bazı yazarlar tarafından, yeniden enfeksiyon riskinin değerlendirilmesinde, protez eklem enfeksiyonu için bir evreleme sistemi tarif edilmiş ve önerilmiştir. Bu evreleme sistemi üç faktörü birleştirir. Birincisi, enfeksiyon tipi (akut operasyon sonrası, akut hematojen, geç kronik) (I, II, III); ikincisi, hastaya ait sistemik riskli durumların derecesi (yani tıbbi komorbit durumlar) ( $A, B, C \ldots)$; üçüncüsü ise, hastaya ait lokal riskli durumların derecesi (yumuşak doku örtüsünün durumu) $(1,2,3 \ldots)$ olarak belirtilmiştir. ${ }^{[83]}$

Tecrübeli bir cerrah, agresif debridmana rağmen, siyatik sinir ve ana damarlara iki aşamalı değişim ile karşılaştırılabilecek ölçüde daha az hasar verebilir.

Birçok araştırmacı tarafından, tek aşamalı değişimi olumlu olarak destekleyen yayınlar bildirilmiştir. ${ }^{[64-66]}$

Bir çalışmada, akut operasyon sonrası enfeksiyonda (<6 hafta), tek aşamalı çimentosuz değişimde, $\% 70$ oranında implantların korunduğu gösterilmiştir. Ancak bu, MRSA varlığında $\% 100$ başarısızlık ile sonuçlanmıştır. ${ }^{[67]}$ Enfekte diz protezinde tek aşamalı değişim; MRSA ve MRSE haricinde tanımlanmış patojen varlığında, iki aşamalı değişime göre daha yüksek diz skorları ve $\% 95$ oranında enfeksiyon kontrolü sağlar. ${ }^{[14]}$ Protezin korunduğu, debridmanın başarısız olduğu vakalarda da tek aşamalı revizyon denenmiş ve başarılı sonuçlar elde edilmiştir. ${ }^{68]}$

Diğer bir çalışmada, iki aşamalı prosedürlerin kadınlarda daha az fayda sağladığı gösterilmiştir. Tekrarlama riskini arttırmadan daha fazla konfor sunmak için, tek aşamalı değişim tercih edilebilir. ${ }^{[69]}$

Dönen menteşeli implantların kullanıldığı, revizyonun sonuçlarının değerlendirildiği 10 yıllık bir seride, tek aşamalı değişim ile posterior kapsül ve kollateral bağların agresif debridmanı sonrası \%93 oranında enfeksiyon kontrolü sağlanmıştır. ${ }^{[70]}$

On iki çalışmanın derlendiği, 1200'den fazla eklemin tek aşamalı değişiminin en az beş yıllık takiplerinde, enfeksiyona rastlanmama oranı \%83'tür. ${ }^{[71]}$ Diğer bir çalışmada, 10 yıllık enfeksiyona rastlanmama oranı \%90 olarak bildirilmiştir. ${ }^{[25]}$ S.aureus ile enfekte kalça ve diz artroplastilerinin olduğu bir çalışmada ise, tek aşamalı değişimin sonuçlarının çift aşamalı değişime göre üstün olduğu bildirilmiştir (\%94'e karşılık \%86). ${ }^{[1]}$ Başka bir çalışmada, kalça ve diz artroplastilerinin tek ve çift aşama 

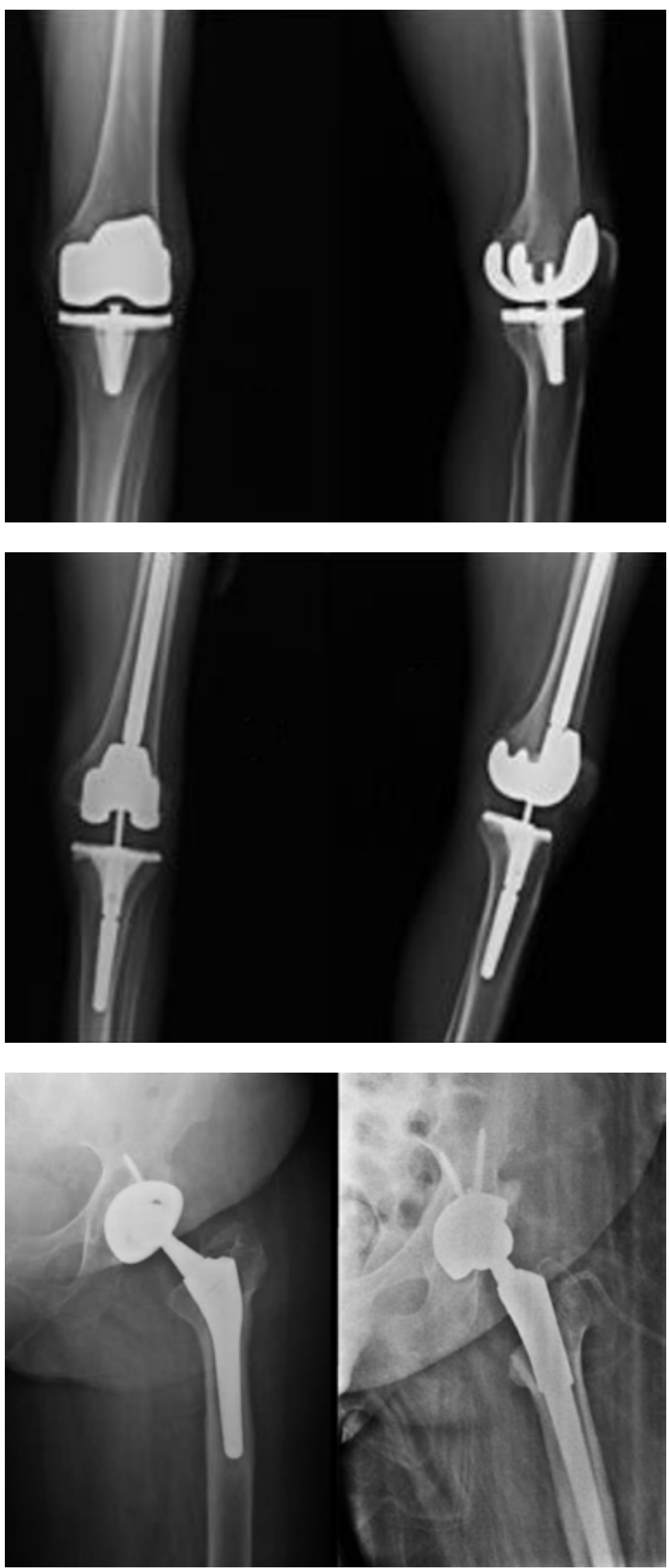

Şekil 1. Enfekte primer total diz artroplastisi; iki yönlü direkt grafi (sol, AP; sağ, lateral) görüntüleri.

Şekil 2. Aynı hastanın tek aşamalı değişim sonrası revizyon total diz artroplastisi; iki yönlü direkt grafi (sol, AP; sağ, lateral) görüntüleri.

Şekil 3. Primer total kalça artroplastisi ve tek aşamalı değişim sonrası revizyon kalça artroplastisi; direkt AP grafi (sağ, primer; sol, revizyon) görüntüleri. 
karşılaştırılmasında iyileşme oranları arasında fark bulunamamıştır. ${ }^{[72]}$ Bir seride ise, kemik defektinin olduğu vakalarda, çimentosuz implantlar ve antibiyotikli allogreftler kullanılmıştır. Tek organizma varlığında vankomisin, çoklu enfeksiyonda vankomisine tobramisin eklenmiştir. Enfeksiyon görülmeme oranı dört yıllık takipte $\% 92$ olmuştur. ${ }^{[73]}$ Akan sinüs varlığında, tek aşamalının başarı oranı \%86 olarak bildirilmiştir. Yine aynı yazarın başka bir çalışmasında, 183 hastanın yedi yıl ve üzerindeki sonuçlarında, başarı oranı \%84 olarak belirtilmiştir. ${ }^{[34,74]}$ Yine 10 yılın üzerinde takipli diğer bir çalışmada, tek aşamalı değişim için \%92'lik başarı oranı bildirilmiştir. ${ }^{[75]}$

İyi bir tedavi planı yapıldığında, tek aşamalı değişim, fungal periprostetik eklem enfeksiyonlarının tedavisinde de etkili bir yöntem olabilir. ${ }^{[76]}$

Diz artroplastisinden ziyade kalça için çimentosuz implant kullanımı, cerrahiden önce etkenin bilinmesi, yıkama yerine komponentlerin revizyonu, operasyon sonrası antibiyotik kullanımı, polimikrobiyal değil monomikrobiyal enfeksiyon varlığı; yeterli yumuşak doku varlığı, immunsüpresan ilaç kullanımı ya da belli komorbid durumlar gibi hastaya ait faktörler varlığına dikkat edilerek, revizyon sonrası yeniden enfeksiyon oranları azaltılabilir. ${ }^{[1]}$

Tek aşamalı değişim artroplastisi araştırmalarının sonuçlarında; omuz eklemi için umut verici, dirsek eklemi için ise şu anda önerilmesine yönelik yetersiz bilginin olduğu belirtilmektedir. ${ }^{[77,78]}$

\section{TARTIŞMA}

Total kalça artroplastisi sonrası enfeksiyon varlığ ; aseptik gevşemeden 2,8 kat, primer artroplastiden ise 4,8 kat fazla maliyete neden olmaktadır. ${ }^{[79]}$ Enfeksiyon, beraberinde artmış bir mortaliteyi getirebilir. Altmış beş yaş hastalarda \%0,4-1,2 oranında, seksen yaş hastalarda ise \%2-7 oranında artmış mortalite bildirilmiştir. ${ }^{[80]}$

Tek aşamalı revizyon prosedürü, maliyeti ve hastanede yatış süresini kısaltarak, mobilizasyonu arttırarak morbiditeyi azaltır. ${ }^{[30,31]}$

Bakterilerin 36 saat ila üç hafta arasında şekillenen biyofilm üretimi ${ }^{[11]}$, enfeksiyonun eradikasyonunda önemli bir yer tutmaktadır. Antibiyotikli çimentolar, ilk iki gün lokal konsantrasyonda yüksek derecede etkin olsalar da, bu etkinlik 3. günden sonra çok çok düşük seviyelere geriler; antibiyotiğe dirençli bakterinin gelişmesine neden olabilir. ${ }^{[82]}$ Vankomisin emdirilmiş allogreft kullanımını, bakteriyi ortadan kaldırmak ve biyofilm tabakaya nüfuz etmek için, yeterince yüksek lokal konsantrasyonları sağlayabilir. ${ }^{[62]}$
Hastaların, enfeksiyona genetik yatkınlığını belirleyebilen girişimleri içeren, biyofilm tabakaları bozan tekniklerin dizaynı ve enfeksiyona dirençli implantların tanıtılması üzerine heyecan verici araştırmalar yapılmaktadır. ${ }^{[83]}$

\section{SONUÇ}

Enfekte artroplasti revizyonunun tedavisinde tek aşamalı değişim, doğru endikasyonlar varlığında başarılı sonuçların elde edilebileceği bir seçenektir. Tek aşamalı değişimin, iki aşamalıya göre kesin olan birtakım avantajları vardır. Bunlar; yalnızca bir operasyon gerektirmesi, sistemik antibiyotik kullanımın süresini ve maliyeti azaltması olarak belirtilebilir. Bu yöntem; uygun hasta seçimi, uygun antibiyotik kullanılması, titiz ve deneyimli bir cerrahi ekip ile başarı şansı artacak bir seçenektir.

\section{KAYNAKLAR}

1. Joulie D, Girard J, Mares O, Beltrand E, Legout L, Dezèque $H$, Migaud $H$, Senneville E. Factors governing the healing of Staphylococcus aureus infections following hip and knee prosthesis implantation: a retrospective study of 95 patients. Orthop Traumatol Surg Res 2011;97(7):685-92. Crossref

2. Toulson C, Walcott-Sapp S, Hur J, Salvati E, Bostrom $\mathrm{M}$, Brause B, Westrich GH. Treatment of infected total hip arthroplasty with a 2-stage reimplantation protocol: update on our institution's experience from 1989 to 2003. J Arthroplasty 2009;24(7):1051-60. Crossref

3. Blom AW, Brown J, Taylor AH, Pattison G, Whitehouse S, Bannister GC.Infection after total knee arthroplasty. J Bone Joint Surg Br 2004;86(5):688-91.

4. Peersman G, Laskin R, Davis J, Peterson M. Infection in total knee replacement: a retrospective review of 6489 total knee replacements. Clin Orthop Relat Res 2001;(392):15-23.

5. Kurtz S, Ong K, Lau E, Mowat F, Halpern M. Projections of primary and revision hip and knee arthroplasty in the United States from 2005 to 2030. J Bone Joint Surg 2007;89(4):780-5.

6. Bozic KJ, Kurtz SM, Lau E, Ong K, Chiu V, Vail TP, Rubash HE, Berry DJ. The epidemiology of revision total knee arthroplasty in the United States. Clin Orthop Relat Res 2010;468(1):4551. Crossref

7. Bozic KJ, Kurtz SM, Lau E, Ong K, Vail TP, Berry DJ. The epidemiology of revision total hip arthroplasty in the United States. J Bone Joint Surg 2009;91(1):128-33. Crossref

8. Kuzyk PR, Dhotar HS, Sternheim A, Gross AE, Safir O, Backstein D. Two-stage revision arthroplasty for management of chronic periprosthetic hip and knee infection: techniques, controversies, and outcomes. J Am Acad Orthop Surg 2014;22(3):153-64. Crossref

9. Zahar A, Webb J, Gehrke T, Kendoff D. One-stage exchange for prosthetic joint infection of the hip. Hip Int 2015;25(4):301-7. Crossref

10. Segawa H, Tsukayama DT, Kyle RF, Becker DA, Gustilo RB. Infection after total knee arthroplasty. A retrospective study of the treatment of eighty-one infections. J Bone Joint Surg 1999;81(10):1434-45. 
11. Toms A, Davidson D, Masri BA, Duncan CP. The management of peri-prosthetic infection in total joint arthroplasty. J Bone Joint Surg Br 2006;88(2):149-55.

12. Buchholz $H$, Elson RA, Engelbrecht $E$, Lodenkämper $H$, Röttger J, Siegel A. Management of deep infection of total hip replacement. J Bone Joint Surg Br 1981;63(3):342-53.

13. Freeman M, Sudlow RA, Casewell MW, Radcliff SS. The management of infected total knee replacements. J Bone Joint Surg Br 1985;67(5):764-8.

14. Singer J, Merz A, Frommelt L, Fink B. High rate of infection control with one-stage revision of septic knee prostheses excluding MRSA and MRSE. Clin Orthop Relat Res 2012;470(5):1461-71. Crossref

15. Zimmerli W, Trampuz A, Ochsner PE. Prosthetic-joint infections. New Engl J Med 2004;351(16):1645-54.

16. Lichstein P, Gehrke T, Lombardi A, Romano C, Stockley I, Babis G, Bialecki J, Bucsi L, Cai X, Cao L, de Beaubien B, Erhardt J, Goodman S, Jiranek W, Keogh P, Lewallen D, Manner P, Marczynski W, Mason JB, Mulhall K, Paprosky W, Patel P, Piccaluga F, Polkowski G, Pulido L, Stockley I, Suarez J, Thorey F, Tikhilov R, Velazquez JD, Winkler H. One-stage vs two-stage exchange. J Arthroplasty 2014;29(2 Suppl):108-11. Crossref

17. Beswick AD, Elvers KT, Smith AJ, Gooberman-Hill R, Lovering A, Blom AW. What is the evidence base to guide surgical treatment of infected hip prostheses? Systematic review of longitudinal studies in unselected patients. BMC Med 2012;10:18. Crossref

18. Klouche S, Sariali E, Mamoudy P. Total hip arthroplasty revision due to infection: a cost analysis approach. Orthop Traumatol Surg Res 2010;96(2):124-32. Crossref

19. Osmon DR, Berbari EF, Berendt AR, Lew D, Zimmerli W, Steckelberg JM, Rao N, Hanssen A, Wilson WR; Infectious Diseases Society of America. Diagnosis and management of prosthetic joint infection: clinical practice guidelines by the Infectious Diseases Society of America. Clin Infect Dis 2013;56(1):e1-e25. Crossref

20. Wongworawat MD. Clinical faceoff: One-versus two-stage exchange arthroplasty for prosthetic joint infections. Clin Orthop Relat Res 2013;471(6):1750-3. Crossref

21. Lu H, Kou B, Lin J. One-stage reimplantation for the salvage of total knee arthroplasty complicated by infection. Zhonghua Wai Ke Za Zhi 1997;35(8):456-8.

22. Parkinson RW, Kay PR, Rawal A. A case for one-stage revision in infected total knee arthroplasty? Knee 2011;18(1):1-4. Crossref

23. von Foerster $G$, Klüber D, Käbler U. Mid- to long-term results after treatment of 118 cases of periprosthetic infections after knee joint replacement using one-stage exchange surgery. Orthopade 1991;20(3):244-52.

24. Engesæter LB, Dale H, Schrama JC, Hallan G, Lie SA. Surgical procedures in the treatment of 784 infected THAs reported to the Norwegian Arthroplasty Register. Acta Orthop 2011;82(5):530-7. Crossref

25. Buechel FF, Femino FP, D'Alessio J. Primary exchange revision arthroplasty for infected total knee replacement: a long-term study. Am J Orthop (Belle Mead NJ)2004;33(4):190-8.

26. Berend KR, Lombardi AV Jr, Morris MJ, Bergeson AG, Adams JB, Sneller MA. Two-stage treatment of hip periprosthetic joint infection is associated with a high rate of infection control but high mortality. Clin Orthop Relat Res 2013;471(2):5108. Crossref
27. Wolf CF, Gu NY, Doctor JN, Manner PA, Leopold SS. Comparison of one and two-stage revision of total hip arthroplasty complicated by infection: a Markov expected-utility decision analysis. J Bone Joint Surg Am 2011;93(7):631-9. Crossref

28. Parvizi J, Gehrke T, Chen AF. Proceedings of the International Consensus on Periprosthetic Joint Infection. Bone Joint J 2013;95-B(11):1450-2. Crossref

29. Oussedik S, Dodd MB, Haddad FS. Outcomes of revision total hip replacement for infection after grading according to a standard protocol. J Bone Joint Surg Br 2010;92(9):1222-6. Crossref

30. George DA, Konan S, Haddad FS. Single-Stage Hip and Knee Exchange for Periprosthetic Joint Infection. J Arthroplasty 2015;30(12):2264-70. Crossref

31. Zeller V, Lhotellier L, Marmor S, Leclerc P, Krain A, Graff W, Ducroquet F, Biau D, Leonard P, Desplaces N, Mamoudy P. One-stage exchange arthroplasty for chronic periprosthetic hip infection: results of a large prospective cohort study. J Bone Joint Surg Am 2014;96(1):e1. Crossref

32. Haddad FS, Bridgens A. Infection following hip replacement: solution options. Orthopedics 2008;31(9):907-8.

33. Haddad FS, Muirhead-Allwood SK, Manktelow AR, BacareseHamilton I. Two-stage uncemented revision hip arthroplasty for infection. J Bone Joint Surg Br 2000;82(5):689-94.

34. Raut W, Siney PD, Wroblewski BM. One-stage revision of infected total hip replacements with discharging sinuses. J Bone Joint Surg Br 1994;76(5):721-4.

35. George DA, Khan M, Haddad FS. Periprosthetic joint infection in total hip arthroplasty: prevention and management. $\mathrm{Br} J$ Hosp Med (Lond) 2015;76(1):12-7. Crossref

36. Gulhane S, Vanhegan S, Haddad FS. Single stage revision: regaining momentum. J Bone Joint Surg Br 2012;94(11 Suppl A):120-2. Crossref

37. Ure KJ, Amstutz HC, Nasser S, Schmalzried TP. Directexchange arthroplasty for the treatment of infection after total hip replacement. An average ten-year follow-up. J Bone Joint Surg Am 1998;80(7):961-8.

38. De Man FH, Sendi P, Zimmerli W, Maurer TB, Ochsner PE, Ilchmann T. Infectiological, functional, and radiographic outcome after revision for prosthetic hip infection according to a strict algorithm. Acta Orthop 2011;82(1):27-34. Crossref

39. Jiranek WA, Waligora AC, Hess SR, Golladay GL. Surgical Treatment of Prosthetic Joint Infections of the Hip and Knee: Changing Paradigms? J Arthroplasty 2015;30(6):912-8. Crossref

40. Vanhegan IS, Morgan-Jones R, Barrett DS, Haddad FS. Developing a strategy to treat established infection in total knee replacement: a review of the latest evidence and clinical practice. J Bone Joint Surg Br 2012;94(7):875-81. Crossref

41. Mereddy P, Pydisetty R, Howard K, Kay PR, Parkinson RW. "2in-1" single stage revision for infected total knee replacement: the wirral and wrightington experience. J Bone Joint Surg Br 2011;93-B:15

42. Atkins BL, Bowler IC. The diagnosis of large joint sepsis. J Hosp Infect 1998;40(4):263-74.

43. Zimmerli W, Lew PD, Waldvogel FA. Pathogenesis of foreign body infection. Evidence for a local granulocyte defect. J Clin Invest 1984;73(4):1191-200. 
44. Della Valle C, Parvizi J, Bauer TW, Dicesare PE, Evans RP, Segreti J, Spangehl M, Watters WC 3rd, Keith M, Turkelson CM, Wies JL, Sluka P, Hitchcock K; American Academy of Orthopaedic Surgeons. Diagnosis of periprosthetic joint infections of the hip and knee. J Am Acad Orthop Surg 2010;18(12):760-70.

45. Levitsky KA, Hozack WJ, Balderston RA, Rothman RH, Gluckman SJ, Maslack MM, Booth RE Jr. Evaluation of the painful prosthetic joint. Relative value of bone scan, sedimentation rate, and joint aspiration. J Arthroplasty $1991 ; 6(3): 237-44$.

46. Wahlig $H$, Dingeldein $E$, Buchholz HW, Buchholz $M$, Bachmann F. Pharmacokinetic study of gentamicin-loaded cement in total hip replacements. Comparative effects of varying dosage. J Bone Joint Surg Br 1984;66(2):175-9.

47. Schäfer P, Fink B, Sandow D, Margull A, Berger I, Frommelt $\mathrm{L}$. Prolonged bacterial culture to identify late periprosthetic joint infection: a promising strategy. Clin Infect Dis 2008;47(11):1403-9. Crossref

48. Trampuz A, Hanssen AD, Osmon DR, Mandrekar J, Steckelberg JM, Patel R. Synovial fluid leukocyte count and differential for the diagnosis of prosthetic knee infection. Am J Med 2004;117(8):556-62.

49. Ghanem E, Parvizi J, Burnett RS, Sharkey PF, Keshavarzi N, Aggarwal A, Barrack RL. Cell count and differential of aspirated fluid in the diagnosis of infection at the site of total knee arthroplasty. J Bone Joint Surg aM 2008;90(8):163743. Crossref

50. Fink B, Gebhard A, Fuerst M, Berger I, Schäfer P. High diagnostic value of synovial biopsy in periprosthetic joint infection of the hip. Clin Orthop Relat Res 2013;471(3):95664. Crossref

51. Fink B, Makowiak C, Fuerst M, Berger I, Schäfer P, Frommelt $\mathrm{L}$. The value of synovial biopsy, joint aspiration and C-reactive protein in the diagnosis of late peri-prosthetic infection of total knee replacements. J Bone Joint Surg Br 2008;90(7):8748. Crossref

52. Urish KL, DeMuth PW, Craft DW, Haider H, Davis CM 3rd. Pulse lavage is inadequate at removal of biofilm from the surface of total knee arthroplasty materials. J Arthroplasty 2014;29(6):1128-32. Crossref

53. Brown NM, Cipriano CA, Moric M, Sporer SM, Della Valle CJ. Dilute betadine lavage before closure for the prevention of acute postoperative deep periprosthetic joint infection. J Arthroplasty 2012;27(1):27-30. Crossref

54. Lineaweaver W, Howard R, Soucy D, McMorris S, Freeman J, Crain C, Robertson J, Rumley T. Topical antimicrobial toxicity. Arch Surg 1985;120(3):267-70.

55. Penner MJ, Masri BA, Duncan CP. Elution characteristics of vancomycin and tobramycin combined in acrylic bonecement. J Arthroplasty 1996;11(8):939-44.

56. Hoad-Reddick D, Evans CR, Norman P, Stockley I. Is there a role for extended antibiotic therapy in a two-stage revision of the infected knee arthroplasty? J Bone Joint Surg $\mathrm{Br}$ 2005;87(2):171-4.

57. Bilgen O, Atici T, Durak K, Karaeminoğullari, Bilgen MS. C-reactive protein values and erythrocyte sedimentation rates after total hip and total knee arthroplasty. J Int Med Res 2001;29(1):7-12

58. Haddad FS, Sukeik M, Alazzawi S. Is single-stage revision according to a strict protocol effective in treatment of chronic knee arthroplasty infections? Clin Orthop Relat Res 2015;473(1):8-14. Crossref
59. Klouche S, Leonard P, Zeller V, Lhotellier L, GraffW, Leclerc P, Mamoudy P, Sariali E. Infected total hip arthroplasty revision: one- or two-stage procedure? Orthop Traumatol Surg Res 2012;98(2):144-50. Crossref

60. Wroblewski B. One-stage revision of infected cemented total hip arthroplasty. Clin Orthop Relat Res 1986;(211):103-7.

61. Loty B, Postel M, Evrard J, Matron P, Courpied JP, Kerboull $M$, Tomeno B. One stage revision of infected total hip replacements with replacement of bone loss by allografts. Study of 90 cases of which 46 used bone allografts. Int Orthop 1992;16(4):330-8.

62. Winkler, $H$. Rationale for one stage exchange of infected hip replacement using uncemented implants and antibiotic impregnated bone graft. Int J Med Sci 2009;6(5):247-52.

63. Choi H-R, Kwon YM, Freiberg AA, Malchau H. Comparison of one-stage revision with antibiotic cement versus twostage revision results for infected total hip arthroplasty. J Arthroplasty 2013;28(8 Suppl):66-70. Crossref

64. Göksan S, Freeman MA. One-stage reimplantation for infected total knee arthroplasty. J Bone Joint Surg $\mathrm{Br}$ 1992;74(1):78-82.

65. Silva M, Tharani R, Schmalzried TP. Results of direct exchange or debridement of the infected total knee arthroplasty. Clin Orthop Relat Res 2002;(404):125-31.

66. Jenny JY, Lengert R, Diesinger Y, Gaudias J, Boeri C, KempfJF. Routine one-stage exchange for chronic infection after total hip replacement. Int Orthop 2014;38(12):2477-81. Crossref

67. Hansen E, Tetreault M, Zmistowski B, Della Valle CJ, Parvizi J, Haddad FS, Hozack WJ. Outcome of one-stage cementless exchange for acute postoperative periprosthetic hip infection. Clin Orthop Relat Res 2013;471(10):3214-22. Crossref

68. Borden LS, Gearen PF. Infected total knee arthroplasty. A protocol for management. J Arthroplasty 1987;2(1):27-36.

69. Massin P, Delory $T$, Lhotellier L, Pasquier G, Roche O, Cazenave A, Estellat $C$, Jenny JY. Infection recurrence factors in one- and two-stage total knee prosthesis exchanges. Knee Surg Sports Traumatol Arthrosc 2015. [Epub ahead of print]

70. Zahar A, Kendoff DO, Klatte TO, Gehrke TA. Can Good Infection Control Be Obtained in One-Stage Exchange of the Infected TKA to a Rotating Hinge Design? 10-year Results. Clin Orthop Relat Res 2016;474(1):81-7. Crossref

71. Moyad TF, Thornhill T, Estok D. Evaluation and management of the infected total hip and knee. Orthopedics 2008;31(6):581-8.

72. Brandt CM, Duffy MCT, Berbari EF, Hanssen AD, Steckelberg JM, Osmon DR. Staphylococcus aureus prosthetic joint infection treated with prosthesis removal and delayed reimplantation arthroplasty. Mayo Clinic Proceedings 1999;74(6):553-8. Crossref

73. Winkler H, Stoiber A, Kaudela K, Winter F, Menschik F. One stage uncemented revision of infected total hip replacement using cancellous allograft bone impregnated with antibiotics. J Bone Joint Surg Br 2008;90(12):1580-4. Crossref

74. Raut W, Siney PD, Wroblewski BM. One-stage revision of total hip arthroplasty for deep infection. Clin Orthop Relat Res 1995;(321):202-7.

75. Callaghan JJ, Katz RP, Johnston RC. One-stage revision surgery of the infected hip. A minimum 10-year followup study. Clin Orthop Relat Res 1999;(369):139-43.

76. Selmon GP, Slater RN, Shepperd JA, Wright EP. Successful 1 -stage exchange total knee arthroplasty for fungal infection. J Arthroplasty 1998;13(1):114-5. 
77. Mook WR, Garrigues GE. Diagnosis and Management of Periprosthetic Shoulder Infections. J Bone Joint Surg Am 2014;96(11):956-65.

78. Somerson JS, Morrey ME, Sanchez-Sotelo J, Morrey BF. Diagnosis and Management of Periprosthetic Elbow Infection. J Bone Joint Surg Am 2015;97(23):1962-71. Crossref

79. Bozic KJ, Ries MD. The impact of infection after total hip arthroplasty on hospital and surgeon resource utilization. J Bone Joint Surg Am 2005;87(8):1746-51.

80. Fisman DN, Reilly DT, Karchmer AW, Goldie SJ. Clinical effectiveness and cost-effectiveness of 2 management strategies for infected total hip arthroplasty in the elderly. Clin Infect Dis 2001;32(3):419-30.
81. Parvizi J, Zmistowski B, Adeli B. Periprosthetic joint infection: treatment options. Orthopedics 2010 33(9):659. Crossref

82. Whiteside LA, Peppers M, Nayfeh TA, Roy ME. Methicillinresistant Staphylococcus aureus in TKA treated with revision and direct intra-articular antibiotic infusion. Clin Orthop Relat Res 2011;469(1):26-33. Crossref

83. Gehrke T, Alijanipour P, Parvizi J. The management of an infected total knee arthroplasty. Bone Joint J 2015;97(10 Suppl A):20-9. Crossref 